Article

\title{
Fuzzy Analytic Hierarchy Process-Based Multi-Criteria Decision Making for Universities Ranking
}

\author{
Rashad Aliyev ${ }^{1, *(D)}$, Hasan Temizkan ${ }^{1}$ (D) and Rafig Aliyev ${ }^{2}$ \\ 1 Department of Mathematics, Faculty of Arts and Sciences, Eastern Mediterranean University, \\ Famagusta 99628, North Cyprus, via Mersin 10, Turkey; hasan.temizkan@emu.edu.tr \\ 2 Azerbaijan State Oil and Industry University, Joint MBA Program, Azadlig ave. 20, AZ1010 Baku, \\ Azerbaijan; r.aliyev@asoiu.edu.az \\ * Correspondence: rashad.aliyev@emu.edu.tr
}

Received: 8 July 2020; Accepted: 10 August 2020; Published: 12 August 2020

\begin{abstract}
High competition between universities has been increasing over the years, and stimulates higher education institutions to attain higher positions in the ranking list. Ranking is an important performance indicator of university status evaluation, and therefore plays an essential role in students' university selection. The ranking of universities has been carried out using different techniques. Main goal of decision processes in real-life problems is to deal with the symmetry or asymmetry of different types of information. We consider that multi-criteria decision making (MCDM) is well applicable to symmetric information modelling. Analytic hierarchy process (AHP) is a well-known technique of MCDM discipline, and is based on pairwise comparisons of criteria/alternatives for alternatives' evaluation. Unfortunately, the classical AHP method is unable to deal with imprecise, vague, and subjective information used for the decision making process in complex problems. So, introducing a more advanced tool for decision making under such circumstances is inevitable. In this paper, fuzzy analytic hierarchy process (FAHP) is applied for the comparison and ranking of performances of five UK universities, according to four criteria. The criteria used for the evaluation of universities' performances are teaching, research, citations, and international outlook. It is proven that applying FAHP approach makes the system consistent, and by the calculation of coefficient of variation for all alternatives, it becomes possible to rank them in prioritized order.
\end{abstract}

Keywords: MCDM; FAHP; ranking; eigenvalue; eigenvector; consistency; coefficient of variation

\section{Introduction}

In the real world, one of the characteristics of being human is having the ability to make appropriate decisions in various situations. These decisions offer benefits and conveniences in every aspect of life. The important elements of decision making process are alternatives and criteria. Decision making is a process of choosing the best alternative among several ones, by considering specific criteria, and this alternative should be suitable for the preferences or beliefs of the decision maker.

Uncertainty is a common phenomenon in the real world. Human decisions which include preferences are mostly vague or uncertain. In other words, the selection of alternatives is performed under the environment filled by complex and imprecise information. As the system complexity increases, uncertainty of problems and in human's thoughts increases consequently. Therefore, there is a need for a system that provides a reliable and precise solution, while dealing with incomplete and uncertain information.

The classical decision making approaches are applied in the presence of certain and complete information. Unfortunately, such approaches are not always capable of providing an exact solution 
of complex problems, and are insufficient to work under many circumstances of real-life situations. For this reason, in order to provide an optimal solution of the problem, fuzzy decision making concept becomes extremely important in the presence of vague information, and this information can be assessed by applying fuzzy set theory, which was firstly proposed by Zadeh in 1965 [1].

Multi-criteria decision making (MCDM) has been a very fast-growing field in recent years. MCDM includes a finite set of alternatives, so that a decision maker can rank them, and there is a finite set of criteria which are weighted by decision maker, with respect to the importance of criteria. So, MCDM is an advanced discipline which can be applied to complex decision making problems, by providing an effective solution for ranking of alternatives. The desired result can be achieved, adhering to the appropriate criteria of the related decision making problem.

Decision making process is important in real-life problems to retrieve the symmetric or asymmetric information. MCDM is an explicitly applied tool to model the information symmetry.

Analytic hierarchy process (AHP) is a frequently used MCDM technique, which was firstly introduced by Thomas Saaty in 1980 [2]. AHP uses criteria and sub-criteria initial weights as well as hierarchical dependencies between criteria [3]. AHP is a powerful structured technique used to organize and analyze complex decisions when the alternatives in a problem are hardly quantified and compared. AHP provides appropriate results if the uncertainty in comparative judgment is not taken into consideration. On the other hand, preferences or judgments of decision makers always include ambiguous expressions and inconsistencies. Moreover, AHP method can cause some problems while dealing with rank reversal problem that means the alternatives' preferences can be reversed in case of adding or deleting any alternative(s), priorities derivations method, the comparison scale [4-11] as well as decision maker's preference aggregation from pairwise comparison matrices in the environment of inaccurate evaluations for determining an appropriate solution for decision making problem [12].

Therefore, AHP is not considered as a convenient method for decision making under uncertainty. Hence, it is necessary to reach better outcomes by using the extension of AHP which is fuzzy analytic hierarchy process (FAHP). Despite the fact that application of fuzzy approach in decision making process using AHP can sometimes lead to disorientation of the eigenvector of the matrix of pairwise comparisons while perturbing the entries of the matrix [13], fuzzy sets can be included in the pairwise comparison to cope with the uncertainty and vagueness in problems. The FAHP model allows decision makers to better specify their preferences in fuzzy environments.

In this paper, FAHP technique is applied on five United Kingdom (UK) universities to be ranked according to the following criteria specified in the well-recognized Times Higher Education data provider: teaching, research, citations, and international outlook.

There exist many publications devoted to the application of FAHP, and some of them are highlighted below.

In [14], fuzzy AHP method is applied on three Dutch universities to demonstrate the performance of the model, and the universities are ranked according to the importance of such criteria as networking and knowledge exchanging ability, general attractiveness, research ability and commercialization ability, and this method can provide obtaining the best university in an uncertain situation.

In [15], fuzzy AHP is used for evaluation of management quality at private higher education. As a case study, STMIC Pringsewu college located in Lampung's Province is used, that needs an improvement in graduates' quality. Six main criteria and 30 sub-criteria are used to make an evaluation of management quality. For this reason, the weights for each criterion are calculated, and ranking of criteria is performed according to the optimal weight.

The knowledge management, leadership effectiveness and organizational culture are the factors used to evaluate the university organizational performance in Taiwan [16]. The results show that the weights of these factors are $55.6 \%, 28.1 \%$ and $16.3 \%$, respectively. So, the knowledge management is defined as being the most significant factor.

An intellectual capital (IC) evaluation model is developed to measure its contribution for the university performances in Taiwan [17]. IC measurement indicators are formulated by using AHP 
method to develop the IC evaluation model. The integration of AHP method and fuzzy approach allows one to eliminate the vagueness on decision makers' judgments, and to develop a hierarchy structure to prioritize the IC measurement indicators for better understanding.

In [18], the selection of university academic staff involving uncertainty is made up by applying fuzzy AHP method. It is mentioned that the AHP model is unable to cope with imprecise judgment in pairwise comparisons, and this disadvantage can be overcome by using fuzzy AHP. Three alternatives based on three criteria are considered in numerical example, where the first criterion is work experience, the second criterion is academic background, and the third criterion is individual skill. The results show that the candidate with the highest normalized weight is determined as the best alternative for employment.

Examining fuzzy AHP for the optimal academic staff selection to be suitable for the required post is studied in [19]. Five candidates are evaluated and ranked according to ten distinct sub-criteria. Since AHP is insufficient to overcome the impreciseness and subjectivity in pairwise comparisons, the fuzzy AHP method becomes an important tool in terms of using fuzzy numbers and linguistic variables to achieve accuracy and consistency. In addition, triangular fuzzy numbers are used to set the fuzzy rating and fuzzy weights.

The combination of fuzzy AHP and fuzzy comprehensive evaluation approach to conduct a teaching performance evaluation is proposed in [20]. The weights of factors and sub-factors are estimated by analysis of fuzzy AHP method, which significantly reduces uncertainty in group decision making. The proposed framework is a useful tool to improve the education quality level in higher education institutions.

In [21], the proposed method evaluates the students' performance in e-learning systems. Six main criteria and 24 sub-criteria are contained in a framework intended for selection of a best student involved, and the criteria weights are calculated by using fuzzy AHP method.

In [22], an e-learning system performance is evaluated on the base of FAHP and critical success factors (CSFs). The evaluation is realized according to seven main CSFs. This performance evaluation helps in the development of strategic planning of e-learning plan.

Fuzzy AHP method is used to assess the ranks of priorities of multiple factors affecting e-learning success in higher education [23]. The study defines the five most influential factors from lecturers' points of view and five most influential factors from students' point of view, to successfully implement the e-learning at Sebelas Maret University.

\section{Preliminaries}

Fuzzy Set. Let $X$ be the universe set of the set of objects and $x$ be the elements of the universe set $X$. Let $y$ be the subset of $X$ which is used for the membership, and the characteristic function $u_{y}$ from $X$ to $\{0,1\}$ can be described as follows:

$$
u_{y}(x)=\left\{\begin{array}{c}
1 \text { if and only if } x \in y \\
0 \text { if and only if } x \notin y
\end{array}\right.
$$

$\{0,1\}$ is the value set where 1 shows the membership and 0 shows non-membership. If the value set is in the interval $[0,1]$, then $A$ is a fuzzy set. Moreover, $u_{y}(x)$ is the degree of membership of elements $x$ in the fuzzy set $\mathrm{y}, u_{y}: X \rightarrow[0,1]$. As much as the value of membership $u_{y}(x)$ for the element $x$ is closer to 1 , then so much element $x$ belongs to the fuzzy set $y$. This fuzzy set $y$ is described as

$$
y=\left\{\left(x, u_{y}(x)\right), x \in X\right\}
$$

where $x$ is an element in the universe set, $u_{y}(x)$ is the degree of membership of $x$ and $X$ is the universe set [24-26].

Fuzzy Number. Triangular Fuzzy Number. Let $y$ be a fuzzy subset of the universe set. Fuzzy number $y$ is a fuzzy subset of real numbers that has important characteristics: 
- $\quad$ The membership function $u_{y}(x)$ is continuous from $\mathrm{R}$ to $[0,1]$.

- The membership function $u_{y}(x)$ is normal, that is, there exists the number $x_{0}$ so that $u_{y}\left(x_{0}\right)=1$.

- If all of the level sets are convex in classical sense for a fuzzy set $y$, that means that this fuzzy set $y$ is convex.

A triangular fuzzy number $y$ can be represented as $\left(y_{l}, y_{m}, y_{r}\right)$. Then, the membership function of the triangular fuzzy number $u_{y}(x)$ can be expressed in the following form [24,25]:

$$
u_{y}(x)=\left\{\begin{array}{llr}
\frac{x-y_{l}}{y_{m}-y_{l}}, & \text { If } y_{l} \leq x \leq y_{m} \\
\frac{y_{u}-x}{y_{u}-y_{m}}, & \text { If } & y_{m} \leq x \leq y_{u} \\
0, & \text { otherwise }
\end{array}\right.
$$

Fuzzy Decision Making. Fuzzy decision making is used to choose the best alternative among several ones in the presence of uncertainty. A set of alternatives $A_{1}, A_{2}, \ldots, A_{n}$ depends on some criteria $H_{1}, H_{2}, \ldots, H_{m}$. So, the best alternative is one that fulfills all criteria [24,25].

Fuzzy Preferences. Fuzzy preferences are actually based on fuzzy logic and fuzzy sets. In MCDM, fuzzy or uncertain preferences can be written as fuzzy utilities or weighted sums. These fuzzy utilities and fuzzy weighted sums are fuzzy numbers. A fuzzy preference is a significant type for fuzzy binary relation, and is used to generate the degree of preference between two alternatives when there are certainty and uncertainty preferences.

Let $A$ represent a set of alternatives $A_{1}, A_{2}, \ldots, A_{n}$ and $n>1$. A fuzzy preference for the set of alternatives $A$ is a fuzzy relation on $A$ denoted by $R=\left(r_{i j}\right)_{\mathrm{nxn}}$ which has a membership function denoted by $u_{R}: A x A[0,1]$. Here, $u_{R}\left(A_{i}, A_{j}\right)=r_{i j}$ represents the degree of preference for alternative $A_{i}$ over $A_{j}$.

\section{Statement of the Problem}

The decision making problem should be stipulated by wide range of alternatives and criteria. In this research, five alternatives and four main criteria are addressed for the university ranking problem. These criteria are teaching, research, citations and international outlook [27].

There are five factors affecting the teaching criterion, which are reputation survey, staff to student ratio, doctorate to bachelor's ratio, doctorates awarded to academic staff ratio and institutional income. Reputation survey, research income and research productivity are the factors affecting the research criterion. Field weighted citation impact is the factor affecting the citations criterion. There are three factors affecting the international outlook criterion which are the proportion of international students, proportion of international staff and international collaboration [27].

Fuzzy AHP has the capability and the power to represent the uncertain situations. This method investigates the pairwise comparisons of alternatives and criteria in terms of importance and dominance of these alternatives and criteria. Fuzzy AHP is frequently used in the solution of complex decision making problems, as it takes into account both qualitative and quantitative factors [28]. Fuzzy comparison matrices are used to tolerate uncertainty. When comparing alternatives, it is required to use uncertainty by the decision maker. For this reason, in such situations, the use of fuzzy numbers is preferred instead of using crisp numbers. In addition, consistency checking is an important factor in the fuzzy AHP method. Consistency checking proves that the constructed fuzzy pairwise matrices are acceptable and consistent $[29,30]$.

The purpose of this paper is a selection of the optimal alternative, among given five alternatives A, B, C, D and E, and this optimal alternative should fit simultaneously all given four criteria.

\section{Methodology}

In addition to many decision-making problems in the field of education, ranking among universities is also considered as a decision-making problem. Main goal in this MCDM problem is to rank the 
universities from the best to the worst by using multiple criteria. In this section, the university ranking problem will be modelled by using the fuzzy AHP method according to eight steps. The steps of fuzzy AHP method are described below:

- Step 1. Construct the fuzzy matrix $\widetilde{C}$ and then decompose it into three matrices called $C_{l}, C_{m}$, $C_{u}$ [31].

- Fuzzy matrix is a matrix with entries as triangular fuzzy numbers. Such a matrix shows the pairwise comparisons of the criteria (mxm matrix) or pairwise comparison of the alternatives with respect to each other (nxn matrix).

- After constructing the fuzzy triangular matrix, it is divided into three matrices as $C_{l}, C_{m}, C_{u}$ which mean matrices of lower, medium and upper values of triangular fuzzy numbers-based entries, respectively.

- Step 2. The three matrices obtained in step 1 will be used in the next step to calculate the system of fuzzy linear homogeneous equations [31].

$$
\begin{gathered}
\bar{C}_{l} w_{l}+\bar{C}_{m} w_{m}+\bar{C}_{u} w_{u}-\bar{\lambda}_{l} w_{l}-\bar{\lambda}_{m} w_{m}-\bar{\lambda}_{u} w_{u}=0 \\
\bar{C}_{l}=2 C_{l}+C_{m}, \bar{C}_{m}=C_{l}+4 C_{m}+C_{u}, \bar{C}_{u}=C_{m}+2 C_{u}
\end{gathered}
$$

- $\quad$ Step 3. Calculate the eigenvalues $\bar{\lambda}_{l}, \bar{\lambda}_{m}, \bar{\lambda}_{u}$ of matrices $\bar{C}_{l}, \bar{C}_{m}, \bar{C}_{u}$ that were determined in step 2. After that, calculate $\lambda_{l}, \lambda_{m}, \lambda_{u}$ by using the following equations [31]:

$$
\bar{\lambda}_{l}=2 \lambda_{l}+\lambda_{m}, \bar{\lambda}_{m}=\lambda_{l}+4 \lambda_{m}+\lambda_{u}, \bar{\lambda}_{u}=\lambda_{m}+2 \lambda_{u}
$$

- $\quad$ Step 4. Calculate the eigenvectors $w_{l}, w_{m}, w_{u}$ of matrices $\bar{C}_{l}, \bar{C}_{m}, \bar{C}_{u}$. Next, calculate $\bar{w}_{l}, \bar{w}_{m}, \bar{w}_{u}$ by using the following formulas [31]:

$$
\begin{gathered}
\bar{w}_{l}=\frac{w_{l} \lambda_{l}}{s_{l} \lambda_{m}}, \bar{w}_{m}=\frac{w_{m}}{s_{m}}, \bar{w}_{u}=\frac{w_{u} \lambda_{u}}{s_{u} \lambda_{m}} \\
s_{l}=\sum_{i=1}^{n} w_{i, l}, \quad s_{m}=\sum_{i=1}^{n} w_{i, m}, \quad s_{u}=\sum_{i=1}^{n} w_{i, u}
\end{gathered}
$$

- Step 5. Calculate the consistency index $(C I)$ and consistency ratio $(C R)$ of the matrix $C_{m}$ by using the following formulas. $C R$ should be $\leq 0.1$ to claim that the comparison matrix is consistent and $R I$ is the random index [31]. $R I$ is used for random consistency which depends on the size of the matrix. The values of random index are recommended by Saaty in [2]. For example, if $n=4$ then $R I=0.90$, if $n=5$ then $R I=1.12$ [31].

$$
C I=\frac{\lambda_{\max }-n}{n-1}, C R=\frac{C I}{R I}
$$

- Step 6. Set the priority fuzzy matrices $\bar{P}_{l}, \bar{P}_{m}, \bar{P}_{u}$ that contain normalized eigenvectors $\bar{w}_{l}, \bar{w}_{m}, \bar{w}_{u}$ of the alternatives with respect to each criterion (use $\bar{w}_{l}^{T}, \bar{w}_{m}{ }^{T}, \bar{w}_{u}{ }^{T}$ ) [32].

- Step 7. Vectors of global priorities $g_{l}, g_{m}, g_{u}$ are calculated according to the following formulas (where $\bar{w}_{l}, \bar{w}_{m}, \bar{w}_{u}$ are the eigenvectors of criteria) [32]:

$$
\begin{aligned}
\bar{w}_{l}^{T} & =\left[\begin{array}{lll}
\bar{w}_{1, l} & \bar{w}_{2, l} & \ldots \bar{w}_{n, l}
\end{array}\right]^{T} \\
\bar{w}_{m}{ }^{T} & =\left[\begin{array}{llll}
\bar{w}_{1, m} & \bar{w}_{2, m} & \ldots \bar{w}_{n, m}
\end{array}\right]^{T}
\end{aligned}
$$




$$
\begin{aligned}
& \bar{w}_{u}^{T}=\left[\begin{array}{llll}
\bar{w}_{1, u} & \bar{w}_{2, u} & \ldots \bar{w}_{n, u}
\end{array}\right]^{T} \\
& g_{l}=\bar{P}_{l} \bar{w}_{l}=\left[\begin{array}{llll}
g_{1, l} & g_{2, l} & \ldots & g_{m, l}
\end{array}\right]^{T} \\
& g_{m}=\bar{P}_{m} \bar{w}_{m}=\left[g_{1, m} g_{2, m} \ldots g_{m, m}\right]^{T} \\
& g_{u}=\bar{P}_{u} \bar{w}_{u}=\left[g_{1, u} g_{2, u} \ldots g_{m, u}\right]^{T}
\end{aligned}
$$

- $\quad$ Step 8. Calculate the expected value (fuzzy mean) and standard deviation (fuzzy spread) by using the following formulas [32]:

$$
\begin{gathered}
g_{i, e}=\frac{g_{i, l}+2 g_{i, m}+g_{u}}{4} \\
\sigma_{i}=\left(\frac{1}{80}\left(3 g_{i, l}{ }^{2}+4 g_{i, m}{ }^{2}+3 g_{i, u}{ }^{2}-4 g_{i, l} g_{i, m}-2 g_{i, l} g_{i, u}-4 g_{i, m} g_{i, u}\right)\right)^{1 / 2}
\end{gathered}
$$

\section{Numerical Example}

An implementation of fuzzy AHP is discussed in this section. The expert's decision about the collected information is mainly up to the amount and characteristics of information affecting its certainty degree. So, error rate of left and right deviations of comparison matrices can be $5 \%, 8 \%, 10 \%$ and so on. Left and right deviations of crisp comparison matrices in [33] are represented with 5\% error rate, as triangular fuzzy number in this example. The eigenvalues, eigenvectors, and consistency are calculated for fuzzy AHP.

\subsection{Fuzzy Pairwise Matrix of Criteria}

Table 1 shows the fuzzy pairwise matrix of criteria.

Table 1. Fuzzy pairwise matrix of criteria.

\begin{tabular}{ccccc}
\hline Criterion & Teaching & Research & Citations & $\begin{array}{c}\text { International } \\
\text { Outlook }\end{array}$ \\
\hline Teaching & $(0.95,1,1.05)$ & $(0.95,1,1.05)$ & $(0.95,1,1.05)$ & $(3.8,4,4.2)$ \\
\hline Research & $(0.95,1,1.05)$ & $(0.95,1,1.05)$ & $(0.95,1,1.05)$ & $(3.8,4,4.2)$ \\
\hline Citations & $(0.95,1,1.05)$ & $(0.95,1,1.05)$ & $(0.95,1,1.05)$ & $(3.8,4,4.2)$ \\
\hline $\begin{array}{c}\text { International } \\
\text { Outlook }\end{array}$ & $(0.2375,0.25,0.2625)$ & $(0.2375,0.25,0.2625)$ & $(0.2375,0.25,0.2625)$ & $(0.95,1,1.05)$ \\
\hline
\end{tabular}

Fuzzy pairwise matrix of criteria is decomposed into three matrices $C_{l}, C_{m}, C_{u}$ as shown in Table 2.

Table 2. Decomposing of fuzzy pairwise matrix of criteria into three matrices $C_{l}, C_{m}, C_{u}$.

\begin{tabular}{cccccccccccc}
\hline \multicolumn{4}{c}{ Matrix $C_{\boldsymbol{l}}$} & \multicolumn{1}{c}{ Matrix $C_{\boldsymbol{m}}$} & \multicolumn{5}{c}{ Matrix $C_{\boldsymbol{u}}$} \\
\hline 0.95 & 0.95 & 0.95 & 3.8 & 1 & 1 & 1 & 4 & 1.05 & 1.05 & 1.05 & 4.2 \\
\hline 0.95 & 0.95 & 0.95 & 3.8 & 1 & 1 & 1 & 4 & 1.05 & 1.05 & 1.05 & 4.2 \\
\hline 0.95 & 0.95 & 0.95 & 3.8 & 1 & 1 & 1 & 4 & 1.05 & 1.05 & 1.05 & 4.2 \\
\hline 0.2375 & 0.2375 & 0.2375 & 0.95 & 0.25 & 0.25 & 0.25 & 1 & 0.2625 & 0.2625 & 0.2625 & 1.05 \\
\hline
\end{tabular}

Then matrices $\bar{C}_{l}, \bar{C}_{m}, \bar{C}_{u}$ of criteria become as in Table 3. 
Table 3. Matrices $\bar{C}_{l}, \bar{C}_{m}, \bar{C}_{u}$ of criteria.

\begin{tabular}{cccccccccccc}
\hline & \multicolumn{2}{c}{ Matrix $\bar{C}_{\boldsymbol{l}}$} & \multicolumn{4}{c}{ Matrix $\bar{C}_{\boldsymbol{m}}$} & \multicolumn{5}{c}{ Matrix $\bar{C}_{\boldsymbol{u}}$} \\
\hline 2.9 & 2.9 & 2.9 & 11.6 & 6 & 6 & 6 & 24 & 3.1 & 3.1 & 3.1 & 12.4 \\
\hline 2.9 & 2.9 & 2.9 & 11.6 & 6 & 6 & 6 & 24 & 3.1 & 3.1 & 3.1 & 12.4 \\
\hline 2.9 & 2.9 & 2.9 & 11.6 & 6 & 6 & 6 & 24 & 3.1 & 3.1 & 3.1 & 12.4 \\
\hline 0.725 & 0.725 & 0.725 & 2.9 & 1.5 & 1.5 & 1.5 & 6 & 0.775 & 0.775 & 0.775 & 3.1 \\
\hline
\end{tabular}

In the next step, the eigenvalues of matrices $\bar{C}_{l}, \bar{C}_{m}$ and $\bar{C}_{u}$ of criteria are calculated. The eigenvalues of these matrices are $\bar{\lambda}_{l}=11.6, \bar{\lambda}_{m}=24, \bar{\lambda}_{u}=12.4$ respectively, and it is obtained that $\lambda_{l}=3.8$, $\lambda_{m}=4, \lambda_{u}=4.2$.

The eigenvectors of matrices $\bar{C}_{l}, \bar{C}_{m}, \bar{C}_{u}$ of criteria are

$w_{l}=\left[\begin{array}{llll}0.5714 & 0.5714 & 0.5714 & 0.1429\end{array}\right]$

$w_{m}=\left[\begin{array}{llll}0.5714 & 0.5714 & 0.5714 & 0.1429\end{array}\right]$

$w_{u}=\left[\begin{array}{llll}0.5714 & 0.5714 & 0.5714 & 0.1429\end{array}\right]$

Then eigenvectors $\bar{w}_{l}, \bar{w}_{m}, \bar{w}_{u}$ of criteria become as

$\bar{w}_{l}=\left[\begin{array}{llll}0.2923 & 0.2923 & 0.2923 & 0.0731\end{array}\right]$

$\bar{w}_{m}=\left[\begin{array}{llll}0.3077 & 0.3077 & 0.3077 & 0.0769\end{array}\right]$

$\bar{w}_{u}=\left[\begin{array}{llll}0.3230 & 0.3230 & 0.3230 & 0.0807\end{array}\right]$

The consistency index and consistency ratio for criteria are calculated as

$$
\begin{aligned}
& C I=(4-4) /(4-1)=0 \\
& C R=0 / 0.9=0 \leq 0.10
\end{aligned}
$$

So, the comparison matrix is completely consistent for criteria.

\subsection{Fuzzy Pairwise Matrix of Teaching Criterion}

Fuzzy pairwise matrix of teaching criterion is represented in Table 4.

Table 4. Fuzzy pairwise matrix of teaching criterion.

\begin{tabular}{cccccc}
\hline Teaching & A & B & C & D & E \\
\hline A & $(0.95,1,1.05)$ & $(0.95,1,1.05)$ & $(1.9,2,2.1)$ & $(2.85,3,3.15)$ & $(0.95,1,1.05)$ \\
\hline B & $(0.95,1,1.05)$ & $(0.95,1,1.05)$ & $(1.9,2,2.1)$ & $(1.9,2,2.1)$ & $(0.95,1,1.05)$ \\
\hline C & $(0.475,0.5,0.525)$ & $(0.475,0.5,0.525)$ & $(0.95,1,1.05)$ & $(0.95,1,1.05)$ & $(0.475,0.5,0.525)$ \\
\hline D & $(0.31635,0.333,0.34965)$ & $(0.475,0.5,0.525)$ & $(0.95,1,1.05)$ & $(0.95,1,1.05)$ & $(0.475,0.5,0.525)$ \\
\hline E & $(0.95,1,1.05)$ & $(0.95,1,1.05)$ & $(1.9,2,2.1)$ & $(1.9,2,2.1)$ & $(0.95,1,1.05)$ \\
\hline
\end{tabular}

Fuzzy pairwise matrix of teaching criterion is decomposed into three matrices $C_{l}, C_{m}, C_{u}$ as shown in Table 5. 
Table 5. Decomposing of fuzzy pairwise matrix of teaching criterion into three matrices $C_{l}, C_{m}, C_{u}$.

\begin{tabular}{ccccccccccccccc}
\hline \multicolumn{4}{c}{ Matrix $C_{\boldsymbol{l}}$} & \multicolumn{4}{c}{ Matrix $C_{m}$} & \multicolumn{5}{c}{ Matrix $C_{u}$} \\
\hline 0.95 & 0.95 & 1.9 & 2.85 & 0.95 & 1 & 1 & 2 & 3 & 1 & 1.05 & 1.05 & 2.1 & 3.15 & 1.05 \\
\hline 0.95 & 0.95 & 1.9 & 1.9 & 0.95 & 1 & 1 & 2 & 2 & 1 & 1.05 & 1.05 & 2.1 & 2.1 & 1.05 \\
\hline 0.475 & 0.475 & 0.95 & 0.95 & 0.475 & 0.5 & 0.5 & 1 & 1 & 0.5 & 0.525 & 0.525 & 1.05 & 1.05 & 0.525 \\
\hline 0.31635 & 0.475 & 0.95 & 0.95 & 0.475 & 0.333 & 0.5 & 1 & 1 & 0.5 & 0.34965 & 0.525 & 1.05 & 1.05 & 0.525 \\
\hline 0.95 & 0.95 & 1.9 & 1.9 & 0.95 & 1 & 1 & 2 & 2 & 1 & 1.05 & 1.05 & 2.1 & 2.1 & 1.05 \\
\hline
\end{tabular}

Then, matrices $\bar{C}_{l}, \bar{C}_{m}, \bar{C}_{u}$ of teaching criterion become as in Table 6 .

Table 6. Matrices $\bar{C}_{l}, \bar{C}_{m}, \bar{C}_{u}$ of teaching criterion.

\begin{tabular}{ccccccccccccccc}
\hline \multicolumn{4}{c}{ Matrix $\bar{C}_{\boldsymbol{l}}$} & \multicolumn{1}{c}{ Matrix $\bar{C}_{m}$} & \multicolumn{4}{c}{ Matrix $\bar{C}_{\boldsymbol{u}}$} \\
\hline 2.9 & 2.9 & 5.8 & 8.7 & 2.9 & 6 & 6 & 12 & 18 & 6 & 3.1 & 3.1 & 6.2 & 9.3 & 3.1 \\
\hline 2.9 & 2.9 & 5.8 & 5.8 & 2.9 & 6 & 6 & 12 & 12 & 6 & 3.1 & 3.1 & 6.2 & 6.2 & 3.1 \\
\hline 1.45 & 1.45 & 2.9 & 2.9 & 1.45 & 3 & 3 & 6 & 6 & 3 & 1.55 & 1.55 & 3.1 & 3.1 & 1.55 \\
\hline 0.9657 & 1.45 & 2.9 & 2.9 & 1.45 & 1.998 & 3 & 6 & 6 & 3 & 1.0323 & 1.55 & 3.1 & 3.1 & 1.55 \\
\hline 2.9 & 2.9 & 5.8 & 5.8 & 2.9 & 6 & 6 & 12 & 12 & 6 & 3.1 & 3.1 & 6.2 & 6.2 & 3.1 \\
\hline
\end{tabular}

The eigenvalues of these matrices are $\bar{\lambda}_{l}=14.5571, \bar{\lambda}_{m}=30.1181, \bar{\lambda}_{u}=15.5610$.

From $\bar{\lambda}_{l}, \bar{\lambda}_{m}, \bar{\lambda}_{u}$, it is obtained that $\lambda_{l}=4.768708, \lambda_{m}=5.019683, \lambda_{u}=5.270658$.

The eigenvectors of matrices $\bar{C}_{l}, \bar{C}_{m}, \bar{C}_{u}$ of teaching criterion are

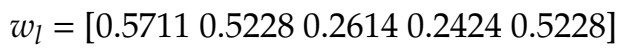

$w_{m}=\left[\begin{array}{lllll}0.5711 & 0.5228 & 0.2614 & 0.2424 & 0.5228\end{array}\right]$

$w_{u}=\left[\begin{array}{lllll}0.5711 & 0.5228 & 0.2614 & 0.2424 & 0.5228\end{array}\right]$

Then eigenvectors $\bar{w}_{l}, \bar{w}_{m}, \bar{w}_{u}$ of teaching criterion become as

$\bar{w}_{l}=\left[\begin{array}{lllll}0.2558 & 0.2342 & 0.1171 & 0.1085 & 0.2342\end{array}\right]$

$\bar{w}_{m}=\left[\begin{array}{lllll}0.2693 & 0.2465 & 0.1232 & 0.1143 & 0.2465\end{array}\right]$

$\bar{w}_{u}=\left[\begin{array}{lllll}0.2827 & 0.2588 & 0.1294 & 0.1200 & 0.2588\end{array}\right]$

The consistency index and consistency ratio for teaching criterion are calculated as

$$
\begin{gathered}
C I=(5.019683-5) /(5-1)=0.004920 \\
C R=0.004920 / 1.12=0.0043 \leq 0.10
\end{gathered}
$$

So, the comparison matrix is consistent for teaching criterion.

\subsection{Fuzzy Pairwise Matrix of Research Criterion}

Fuzzy pairwise matrix of research criterion is represented in Table 7. 
Table 7. Fuzzy pairwise matrix of research criterion.

\begin{tabular}{cccccc}
\hline Research & A & B & C & D & E \\
\hline A & $(0.95,1,1.05)$ & $(0.95,1,1.05)$ & $(1.9,2,2.1)$ & $(2.85,3,3.15)$ & $(1.9,2,2.1)$ \\
\hline B & $(0.95,1,1.05)$ & $(0.95,1,1.05)$ & $(0.95,1,1.05)$ & $(1.9,2,2.1)$ & $(0.95,1,1.05)$ \\
\hline C & $(0.475,0.5,0.525)$ & $(0.95,1,1.05)$ & $(0.95,1,1.05)$ & $(0.95,1,1.05)$ & $(0.95,1,1.05)$ \\
\hline D & $(0.31635,0.333,0.34965)$ & $(0.475,0.5,0.525)$ & $(0.95,1,1.05)$ & $(0.95,1,1.05)$ & $(0.475,0.5,0.525)$ \\
\hline E & $(0.475,0.5,0.525)$ & $(0.95,1,1.05)$ & $(0.95,1,1.05)$ & $(1.9,2,2.1)$ & $(0.95,1,1.05)$ \\
\hline
\end{tabular}

Fuzzy pairwise matrix of research criterion is decomposed into three matrices $C_{l}, C_{m}, C_{u}$ as shown in Table 8.

Table 8. Decomposing of fuzzy pairwise matrix of research criterion into three matrices $C_{l}, C_{m}, C_{u}$.

\begin{tabular}{ccccccccccccccc}
\hline \multicolumn{4}{c}{ Matrix $C_{\boldsymbol{l}}$} & \multicolumn{4}{c}{ Matrix $C_{m}$} & \multicolumn{5}{c}{ Matrix $C_{u}$} \\
\hline 0.95 & 0.95 & 1.9 & 2.85 & 1.9 & 1 & 1 & 2 & 3 & 2 & 1.05 & 1.05 & 2.1 & 3.15 & 2.1 \\
\hline 0.95 & 0.95 & 0.95 & 1.9 & 0.95 & 1 & 1 & 1 & 2 & 1 & 1.05 & 1.05 & 1.05 & 2.1 & 1.05 \\
\hline 0.475 & 0.95 & 0.95 & 0.95 & 0.95 & 0.5 & 1 & 1 & 1 & 1 & 0.525 & 1.05 & 1.05 & 1.05 & 1.05 \\
\hline 0.31635 & 0.475 & 0.95 & 0.95 & 0.475 & 0.333 & 0.5 & 1 & 1 & 0.5 & 0.34965 & 0.525 & 1.05 & 1.05 & 0.525 \\
\hline 0.475 & 0.95 & 0.95 & 1.9 & 0.95 & 0.5 & 1 & 1 & 2 & 1 & 0.525 & 1.05 & 1.05 & 2.1 & 1.05 \\
\hline
\end{tabular}

Then, matrices $\bar{C}_{l}, \bar{C}_{m}, \bar{C}_{u}$ of research criterion become as in Table 9 .

Table 9. Matrices $\bar{C}_{l}, \bar{C}_{m}, \bar{C}_{u}$ of research criterion.

\begin{tabular}{ccccccccccccccc}
\hline \multicolumn{4}{c}{ Matrix $\bar{C}_{\boldsymbol{l}}$} & \multicolumn{1}{c}{ Matrix $\bar{C}_{\boldsymbol{m}}$} & \multicolumn{4}{c}{ Matrix $\bar{C}_{\boldsymbol{u}}$} \\
\hline 2.9 & 2.9 & 5.8 & 8.7 & 5.8 & 6 & 6 & 12 & 18 & 12 & 3.1 & 3.1 & 6.2 & 9.3 & 6.2 \\
\hline 2.9 & 2.9 & 2.9 & 5.8 & 2.9 & 6 & 6 & 6 & 12 & 6 & 3.1 & 3.1 & 3.1 & 6.2 & 3.1 \\
\hline 1.45 & 2.9 & 2.9 & 2.9 & 2.9 & 3 & 6 & 6 & 6 & 6 & 1.55 & 3.1 & 3.1 & 3.1 & 3.1 \\
\hline 0.9657 & 1.45 & 2.9 & 2.9 & 1.45 & 1.998 & 3 & 6 & 6 & 3 & 1.0323 & 1.55 & 3.1 & 3.1 & 1.55 \\
\hline 1.45 & 2.9 & 2.9 & 5.8 & 2.9 & 3 & 6 & 6 & 12 & 6 & 1.55 & 3.1 & 3.1 & 6.2 & 3.1 \\
\hline
\end{tabular}

The eigenvalues of these matrices are $\bar{\lambda}_{l}=14.7725, \bar{\lambda}_{m}=30.5637, \bar{\lambda}_{u}=15.7912$ and $\lambda_{l}=4.839275, \lambda_{m}=5.09395, \lambda_{u}=5.348625$.

The eigenvectors of matrices $\bar{C}_{l}, \bar{C}_{m}, \bar{C}_{u}$ of research criterion are

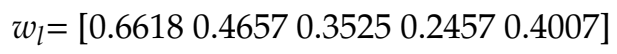

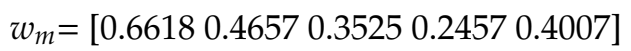

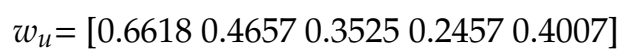

Then eigenvectors $\bar{w}_{l}, \bar{w}_{m}, \bar{w}_{u}$ of research criterion become as

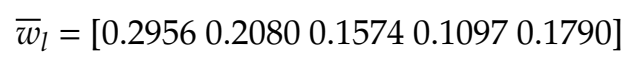

$\bar{w}_{m}=\left[\begin{array}{lllll}0.3112 & 0.2190 & 0.1657 & 0.1155 & 0.1884\end{array}\right]$

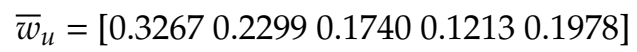

The consistency index and consistency ratio for research criterion are

$$
\begin{gathered}
C I=(5.09395-5) /(5-1)=0.0234875 \\
C R=0.0234875 / 1.12=0.0209709821 \leq 0.10
\end{gathered}
$$

So, the comparison matrix is consistent for research criterion. 


\subsection{Fuzzy Pairwise Matrix of Citations Criterion}

Table 10 shows the fuzzy pairwise matrix of citations criterion.

Table 10. Fuzzy pairwise matrix of citations criterion.

\begin{tabular}{cccccc}
\hline Citations & A & B & C & D & E \\
\hline A & $(0.95,1,1.05)$ & $(0.95,1,1.05)$ & $(0.95,1,1.05)$ & $(0.95,1,1.05)$ & $(2.85,3,3.15)$ \\
\hline B & $(0.95,1,1.05)$ & $(0.95,1,1.05)$ & $(0.95,1,1.05)$ & $(0.95,1,1.05)$ & $(2.85,3,3.15)$ \\
\hline C & $(0.95,1,1.05)$ & $(0.95,1,1.05)$ & $(0.95,1,1.05)$ & $(0.95,1,1.05)$ & $(2.85,3,3.15)$ \\
\hline D & $(0.95,1,1.05)$ & $(0.95,1,1.05)$ & $(0.95,1,1.05)$ & $(0.95,1,1.05)$ & $(1.9,2,2.1)$ \\
\hline E & $(0.31635,0.333,0.34965)$ & $(0.31635,0.333,0.34965)$ & $(0.31635,0.333,0.34965)$ & $(0.475,0.5,0.525)$ & $(0.95,1,1.05)$ \\
\hline
\end{tabular}

Fuzzy pairwise matrix of citations criterion is decomposed into three matrices $C_{l}, C_{m}, C_{u}$ as shown in Table 11.

Table 11. Decomposing of fuzzy pairwise matrix of citations criterion into three matrices $C_{l}, C_{m}, C_{u}$.

\begin{tabular}{ccccccccccccccc}
\hline \multicolumn{3}{c}{ Matrix $C_{\boldsymbol{l}}$} & \multicolumn{4}{c}{ Matrix $C_{m}$} & \multicolumn{5}{c}{ Matrix $C_{\boldsymbol{u}}$} \\
\hline 0.95 & 0.95 & 0.95 & 0.95 & 2.85 & 1 & 1 & 1 & 1 & 3 & 1.05 & 1.05 & 1.05 & 1.05 & 3.15 \\
\hline 0.95 & 0.95 & 0.95 & 0.95 & 2.85 & 1 & 1 & 1 & 1 & 3 & 1.05 & 1.05 & 1.05 & 1.05 & 3.15 \\
\hline 0.95 & 0.95 & 0.95 & 0.95 & 2.85 & 1 & 1 & 1 & 1 & 3 & 1.05 & 1.05 & 1.05 & 1.05 & 3.15 \\
\hline 0.95 & 0.95 & 0.95 & 0.95 & 1.9 & 1 & 1 & 1 & 1 & 2 & 1.05 & 1.05 & 1.05 & 1.05 & 2.1 \\
\hline 0.31635 & 0.31635 & 0.31635 & 0.475 & 0.95 & 0.333 & 0.333 & 0.333 & 0.5 & 1 & 0.34965 & 0.34965 & 0.34965 & 0.525 & 1.05 \\
\hline
\end{tabular}

Then, matrices $\bar{C}_{l}, \bar{C}_{m}, \bar{C}_{u}$ of citations criterion become as in Table 12 .

Table 12. Matrices $\bar{C}_{l}, \bar{C}_{m}, \bar{C}_{u}$ of citations criterion.

\begin{tabular}{ccccccccccccccc}
\hline \multicolumn{4}{c}{} & \multicolumn{1}{c}{ Matrix $\bar{C}_{\boldsymbol{l}}$} & \multicolumn{4}{c}{ Matrix $\bar{C}_{m}$} & \multicolumn{5}{c}{ Matrix $\bar{C}_{\boldsymbol{u}}$} \\
\hline 2.9 & 2.9 & 2.9 & 2.9 & 8.7 & 6 & 6 & 6 & 6 & 18 & 3.1 & 3.1 & 3.1 & 3.1 & 9.3 \\
\hline 2.9 & 2.9 & 2.9 & 2.9 & 8.7 & 6 & 6 & 6 & 6 & 18 & 3.1 & 3.1 & 3.1 & 3.1 & 9.3 \\
\hline 2.9 & 2.9 & 2.9 & 2.9 & 8.7 & 6 & 6 & 6 & 6 & 18 & 3.1 & 3.1 & 3.1 & 3.1 & 9.3 \\
\hline 2.9 & 2.9 & 2.9 & 2.9 & 5.8 & 6 & 6 & 6 & 6 & 12 & 3.1 & 3.1 & 3.1 & 3.1 & 6.2 \\
\hline 0.9657 & 0.9657 & 0.9657 & 1.45 & 2.9 & 1.998 & 1.998 & 1.998 & 3 & 6 & 1.0323 & 1.0323 & 1.0323 & 1.55 & 3.1 \\
\hline
\end{tabular}

The eigenvalues of these matrices are $\bar{\lambda}_{l}=14.5559, \bar{\lambda}_{m}=30.1157, \bar{\lambda}_{u}=15.5598$ and $\lambda_{l}=4.768308$, $\lambda_{m}=5.019283, \lambda_{u}=5.270258$.

The eigenvectors of matrices $\bar{C}_{l}, \bar{C}_{m}, \bar{C}_{u}$ of citations criterion are

$w_{l}=\left[\begin{array}{lll}0.5005 & 0.50050 .50050 .46420 .1821\end{array}\right]$

$w_{m}=\left[\begin{array}{lll}0.5005 & 0.50050 .50050 .46420 .1821\end{array}\right]$

$w_{u}=\left[\begin{array}{ll}0.50050 .50050 .50050 .46420 .1821\end{array}\right]$

Then eigenvectors $\bar{w}_{l}, \bar{w}_{m}, \bar{w}_{u}$ of citations criterion become as

$$
\begin{aligned}
& \bar{w}_{l}=\left[\begin{array}{lllll}
0.2213 & 0.2213 & 0.2213 & 0.2053 & 0.0805
\end{array}\right] \\
& \bar{w}_{m}=\left[\begin{array}{lllll}
0.2330 & 0.2330 & 0.2330 & 0.2161 & 0.0847
\end{array}\right] \\
& \bar{w}_{u}=\left[\begin{array}{lllll}
0.2446 & 0.2446 & 0.2446 & 0.2269 & 0.0890
\end{array}\right]
\end{aligned}
$$

The consistency index and consistency ratio for citations criterion are

$$
C I=(5.019283-5) /(5-1)=0.00482075
$$




$$
C R=0.00482075 / 1.12=0.0043042411 \leq 0.10
$$

So, the comparison matrix is consistent with the citations criterion.

\subsection{Fuzzy Pairwise Matrix of International Outlook Criterion}

Table 13 shows the fuzzy pairwise matrix of international outlook criterion.

Table 13. Fuzzy pairwise matrix of international outlook criterion.

\begin{tabular}{cccccc}
\hline Inter. Outlook & A & B & C & D & E \\
\hline A & $(0.95,1,1.05)$ & $(0.95,1,1.05)$ & $(0.95,1,1.05)$ & $(0.95,1,1.05)$ & $(0.95,1,1.05)$ \\
\hline B & $(0.95,1,1.05)$ & $(0.95,1,1.05)$ & $(0.95,1,1.05)$ & $(0.95,1,1.05)$ & $(0.95,1,1.05)$ \\
\hline C & $(0.95,1,1.05)$ & $(0.95,1,1.05)$ & $(0.95,1,1.05)$ & $(0.95,1,1.05)$ & $(0.95,1,1.05)$ \\
\hline D & $(0.95,1,1.05)$ & $(0.95,1,1.05)$ & $(0.95,1,1.05)$ & $(0.95,1,1.05)$ & $(0.95,1,1.05)$ \\
\hline E & $(0.95,1,1.05)$ & $(0.95,1,1.05)$ & $(0.95,1,1.05)$ & $(0.95,1,1.05)$ & $(0.95,1,1.05)$ \\
\hline
\end{tabular}

Fuzzy pairwise matrix of international outlook criterion is decomposed into three matrices $C_{l}, C_{m}, C_{u}$ as shown in Table 14.

Table 14. Decomposing of fuzzy pairwise matrix of international outlook criterion into three matrices $C_{l}, C_{m}, C_{u}$.

\begin{tabular}{lllllllllllllll}
\hline \multicolumn{4}{c}{ Matrix $C_{\boldsymbol{l}}$} & \multicolumn{4}{c}{ Matrix $C_{m}$} & \multicolumn{1}{c}{ Matrix $C_{\boldsymbol{u}}$} \\
\hline 0.95 & 0.95 & 0.95 & 0.95 & 0.95 & 1 & 1 & 1 & 1 & 1 & 1.05 & 1.05 & 1.05 & 1.05 & 1.05 \\
\hline 0.95 & 0.95 & 0.95 & 0.95 & 0.95 & 1 & 1 & 1 & 1 & 1 & 1.05 & 1.05 & 1.05 & 1.05 & 1.05 \\
\hline 0.95 & 0.95 & 0.95 & 0.95 & 0.95 & 1 & 1 & 1 & 1 & 1 & 1.05 & 1.05 & 1.05 & 1.05 & 1.05 \\
\hline 0.95 & 0.95 & 0.95 & 0.95 & 0.95 & 1 & 1 & 1 & 1 & 1 & 1.05 & 1.05 & 1.05 & 1.05 & 1.05 \\
\hline 0.95 & 0.95 & 0.95 & 0.95 & 0.95 & 1 & 1 & 1 & 1 & 1 & 1.05 & 1.05 & 1.05 & 1.05 & 1.05 \\
\hline
\end{tabular}

Then, matrices $\bar{C}_{l}, \bar{C}_{m}, \bar{C}_{u}$ of international outlook criterion become as in Table 15 .

Table 15. Matrices $\bar{C}_{l}, \bar{C}_{m}, \bar{C}_{u}$ of international outlook criterion.

\begin{tabular}{lllllllllllllll}
\hline & \multicolumn{4}{c}{ Matrix $\bar{C}_{\boldsymbol{l}}$} & \multicolumn{4}{c}{ Matrix $\bar{C}_{\boldsymbol{m}}$} & \multicolumn{4}{c}{ Matrix $\bar{C}_{\boldsymbol{u}}$} \\
\hline 2.9 & 2.9 & 2.9 & 2.9 & 2.9 & 6 & 6 & 6 & 6 & 6 & 3.1 & 3.1 & 3.1 & 3.1 & 3.1 \\
\hline 2.9 & 2.9 & 2.9 & 2.9 & 2.9 & 6 & 6 & 6 & 6 & 6 & 3.1 & 3.1 & 3.1 & 3.1 & 3.1 \\
\hline 2.9 & 2.9 & 2.9 & 2.9 & 2.9 & 6 & 6 & 6 & 6 & 6 & 3.1 & 3.1 & 3.1 & 3.1 & 3.1 \\
\hline 2.9 & 2.9 & 2.9 & 2.9 & 2.9 & 6 & 6 & 6 & 6 & 6 & 3.1 & 3.1 & 3.1 & 3.1 & 3.1 \\
\hline 2.9 & 2.9 & 2.9 & 2.9 & 2.9 & 6 & 6 & 6 & 6 & 6 & 3.1 & 3.1 & 3.1 & 3.1 & 3.1 \\
\hline
\end{tabular}

The eigenvalues of these matrices are $\bar{\lambda}_{l}=14.5, \bar{\lambda}_{m}=30, \bar{\lambda}_{u}=15.5$ and $\lambda_{l}=4.75, \lambda_{m}=5, \lambda_{u}=5.25$.

The eigenvectors of matrices $\bar{C}_{l}, \bar{C}_{m}, \bar{C}_{u}$ of international outlook criterion are

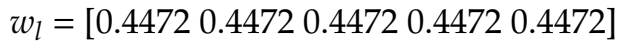

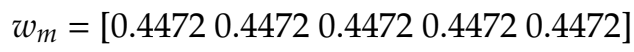

$w_{u}=\left[\begin{array}{lll}0.4472 & 0.44720 .44720 .44720 .4472\end{array}\right]$ 
Then eigenvectors $\bar{w}_{l}, \bar{w}_{m}, \bar{w}_{u}$ of international outlook criterion become as

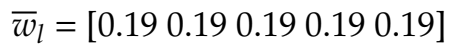

$\bar{w}_{m}=\left[\begin{array}{lllll}0.2 & 0.2 & 0.2 & 0.2 & 0.2\end{array}\right]$

$\bar{w}_{u}=\left[\begin{array}{lllll}0.21 & 0.21 & 0.21 & 0.21 & 0.21\end{array}\right]$

The consistency index and consistency ratio for international outlook criterion are

$$
\begin{aligned}
& C I=(5-5) /(5-1)=0 \\
& C R=0 / 1.12=0 \leq 0.10
\end{aligned}
$$

So, the comparison matrix is completely consistent for international outlook criterion.

Priority fuzzy matrices $\bar{P}_{l}, \bar{P}_{m}, \bar{P}_{u}$ that contain normalized eigenvectors $\bar{w}_{l}, \bar{w}_{m}, \bar{w}_{u}$ are given below:

$$
\begin{gathered}
\bar{P}_{l}=\left[\begin{array}{llll}
0.2558 & 0.2956 & 0.2213 & 0.19 \\
0.2342 & 0.2080 & 0.2213 & 0.19 \\
0.1171 & 0.1574 & 0.2213 & 0.19 \\
0.1085 & 0.1097 & 0.2053 & 0.19 \\
0.2342 & 0.1790 & 0.0805 & 0.19
\end{array}\right] \\
\bar{P}_{m}=\left[\begin{array}{llll}
0.2693 & 0.3112 & 0.2330 & 0.2 \\
0.2465 & 0.2190 & 0.2330 & 0.2 \\
0.1232 & 0.1657 & 0.2330 & 0.2 \\
0.1143 & 0.1155 & 0.2161 & 0.2 \\
0.2465 & 0.1884 & 0.0847 & 0.2
\end{array}\right] \\
\bar{P}_{u}=\left[\begin{array}{llll}
0.2827 & 0.3267 & 0.2446 & 0.21 \\
0.2588 & 0.2299 & 0.2446 & 0.21 \\
0.1294 & 0.1740 & 0.2446 & 0.21 \\
0.1200 & 0.1213 & 0.2269 & 0.21 \\
0.2588 & 0.1978 & 0.0890 & 0.21
\end{array}\right]
\end{gathered}
$$

Eigenvectors of criteria are

$$
\begin{aligned}
& \bar{w}_{l}=\left[\begin{array}{llll}
0.2923 & 0.2923 & 0.2923 & 0.0731
\end{array}\right] \\
& \bar{w}_{m}=\left[\begin{array}{llll}
0.3077 & 0.3077 & 0.3077 & 0.0769
\end{array}\right] \\
& \bar{w}_{u}=\left[\begin{array}{llll}
0.3230 & 0.3230 & 0.3230 & 0.0807
\end{array}\right]
\end{aligned}
$$

By multiplying priority fuzzy matrices $\bar{P}_{l}, \bar{P}_{m}, \bar{P}_{u}$ by $\bar{w}_{l}, \bar{w}_{m}, \bar{w}_{u}$, the global priorities are obtained. Table 16 represents global priorities, expected value, standard deviation and coefficient of variation.

Table 16. Global Priorities, Expected Value, Standard Deviation and Coefficient of Variation.

\begin{tabular}{ccccccc}
\hline \multirow{2}{*}{ Alternative } & $\begin{array}{c}\text { Vector } \\
g_{l}\end{array}$ & $\begin{array}{c}\text { Vector } \\
g_{m}\end{array}$ & $\begin{array}{c}\text { Vector } \\
g_{u}\end{array}$ & $\begin{array}{c}\text { Exp. Val. } \\
g_{i, \boldsymbol{e}}\end{array}$ & $\begin{array}{c}\text { Stand. } \\
\text { Dev. (\%) }\end{array}$ & $\mathbf{C V}_{\mathbf{i}}$ \\
\hline A & 0.2397 & 0.2657 & 0.2928 & 0.2660 & 0.8397 & 3.1568 \\
\hline B & 0.2078 & 0.2303 & 0.2538 & 0.2306 & 0.7274 & 3.1544 \\
\hline C & 0.1588 & 0.1760 & 0.1940 & 0.1762 & 0.5566 & 3.1589 \\
\hline D & 0.1377 & 0.1526 & 0.1682 & 0.1528 & 0.4823 & 3.1564 \\
\hline E & 0.1582 & 0.1753 & 0.1932 & 0.1755 & 0.5535 & 3.1538 \\
\hline
\end{tabular}


According to [32], the alternative with higher expected value and lower standard deviation should be considered as the best one. Apart from the obtained results for these measures in Table 16, there is no possibility to rank the universities under such circumstances. For this reason, ranking can only be possible according to the values of coefficient of variation $\left(\mathrm{CV}_{\mathrm{i}}=\sigma_{i} / g_{i, e}\right)$, which are also represented in Table 16. An alternative with a smaller $\mathrm{CV}_{\mathrm{i}}$ is taken as the best one [32]. So, the universities $\mathrm{E}$ and $\mathrm{C}$ are respectively best and worst alternatives, according to the results of coefficient of variation $\left(\mathrm{CV}_{\mathrm{i}}\right)$. Ranking of the universities has the prioritized order $E>B>D>A>C$.

\section{Conclusions}

The quality of a university is stipulated by its ranking in the international higher education sector; in other words, ranking is a tool which is used to measure the university performance. Selecting a prestigious university to study is a process that requires strategic decision making. Nowadays, most decisions are made in complex and uncertain environments. When the complexity of a decision making problem increases, it becomes difficult to reach the perfect solution. In such cases, a better decision making method and more precise results are required. Fuzzy AHP method can be a very useful tool for optimal problem solving. Since fuzzy AHP provides precise results in cases of uncertainty, it is one of the most widely used approaches among MCDM methodologies. In this paper, fuzzy AHP is applied to rank five UK universities according to four criteria. These criteria are teaching, research, citations and international outlook. After checking the consistency of all criteria and alternatives' pairwise matrices, their eigenvectors are calculated. By using these eigenvectors, the ranking of five universities is carried out.

Author Contributions: Conceptualization and statement of the problem belong to R.A. (Rashad Aliyev) and R.A. (Rafig Aliyev); Reviewing and editing of the paper belong to R.A. (Rashad Aliyev) and H.T.; Calculation of eigenvalues and eigenvectors of matrices as well as testing of obtained results belong to H.T. and R.A. (Rafig Aliyev). All authors have read and agreed to the published version of the manuscript.

Funding: This research received no external funding.

Conflicts of Interest: The authors declare no conflict of interest.

\section{References}

1. Zadeh, L.A. Fuzzy sets. Inf. Control 1965, 8, 338-353. [CrossRef]

2. Saaty, T.L. The Analytic Hierarchy Process; McGraw-Hill International: New York, NY, USA, 1980.

3. Ziemba, P. Inter-Criteria Dependencies-Based Decision Support in the Sustainable Wind Energy Management. Energies 2019, 12, 749. [CrossRef]

4. Johnson, C.R.; Beine, W.B.; Wang, T.J. Right-left asymmetry in an eigenvector ranking procedure. J. Math. Psychol. 1979, 19, 61-64. [CrossRef]

5. Wang, Y.M.; Luo, Y. On rank reversal in decision analysis. Math Comput Model 2009, 49, 1221-1229. [CrossRef]

6. Barzilai, J. Basic Principles of Measurement. Conf. Proc. IEEE Int. Conf. Syst. Man. Cybern. 2001, 1, 395-400.

7. Ishizaka, A.; Lusti, M. How to derive priorities in AHP: A comparative study. Cent. Eur. J. Oper. Res. 2006, 14, 387-400. [CrossRef]

8. Ishizaka, A.; Labib, A. Analytic Hierarchy Process and Expert Choice: Benefits and limitations. OR Insight 2009, 22, 201-220. [CrossRef]

9. Barzilai, J. Notes on the Analytic Hierarchy Process. In Proceedings of the NSF Design and Manufacturing Research Conference, Tampa, FL, USA; 2001; pp. 1-6. Available online: http://www.scientificmetrics. com/downloads/publications/Barzilai_2001_Notes_on_the_Analytic_Hierarchy_Process.pdf (accessed on 7 July 2020). 
10. Barzilai, J. Notes on Measurement and Decision Theory. In Proceedings of the NSF Design and Manufacturing Research Conference, Tampa, FL, USA; 2002; pp. 1-11. Available online: https://scholar.google.com/scholar? q=Barzilai \%2C\%20J.\%3A\%20Notes\%20on\%20measurement $\% 20$ and $\% 20$ Decision $\% 20$ Theory. $\% 20 I n \% 3 \mathrm{~A} \%$ 20Proceedings $\% 20$ of $\% 20$ the $\% 20$ NSF\%20Design $\% 20$ and $\% 20$ Manufacturing\%20Research $\% 20$ Conference $\%$ 2C\%20San\%20Juan\%2C\%20Puerto\%20Rico\%2C\%20pp.\%201\%E2\%80\%9311\%20\%282002\%29 (accessed on 7 July 2020).

11. Ziemba, P.; Watróbski, J. Selected Issues of Rank Reversal Problem in ANP Method. In Selected Issues in Experimental Economics. Springer Proceedings in Business and Economics; Nermend, K., Łatuszyńska, M., Eds.; Springer: Berlin/Heidelberg, Germany, 2016; pp. 203-225. Available online: https://link.springer.com/chapter/ 10.1007/978-3-319-28419-4_14 (accessed on 7 July 2020).

12. Ziemba, P.; Watróbski, J.; Jankowski, J.; Piwowarski, M. Research on the Properties of the AHP in the Environment of Inaccurate Expert Evaluations. In Selected Issues in Experimental Economics. Springer Proceedings in Business and Economics; Nermend, K., Łatuszyńska, M., Eds.; Springer: Berlin/Heidelberg, Germany, 2016; pp. 227-243. Available online: https://link.springer.com/chapter/10.1007/978-3-319-28419-4_15 (accessed on 7 July 2020).

13. Saaty, T.L. The Analytic Hierarchy and Analytic Network Measurement Processes: Applications to Decisions under Risk. Eur. J. Pure. Appl. Math. 2008, 1, 122-196.

14. Salimi, N.; Rezaei, J. Multi-criteria university selection: Formulation and implementation using a fuzzy AHP. J. Syst. Sci. Syst. Eng. 2015, 24, 293-315. [CrossRef]

15. Abadi, S.; Widyarto, S. The model of determining quality of management private higher education using FAHP (Fuzzy Analytic Hierarchy Process) method. ICESIA 2016, 1, 166-172.

16. Chi, H.K.; Yeh, H.R.; Liao, L.H. Applying fuzzy analytic hierarchy process to explore the university organizational performance in Taiwan. J. Hum. Resour. Adult Learn. 2008, 4, 39-46.

17. Lee, S.H. Using fuzzy AHP to develop intellectual capital evaluation model for assessing their performance contribution in a university. Expert Syst. Appl. 2010, 37, 4941-4947. [CrossRef]

18. Asuquo, D.E.; Onuodu, F.E. A fuzzy AHP model for selection of university academic staff. Int. J. Comput. Appl. 2016, 141, 19-26.

19. Rouyendegh, B.D.; Erkan, T.E. Selection of academic staff using the fuzzy analytic hierarchy process (FAHP): A pilot study. Tech. Gaz. 2012, 19, 923-929.

20. Chen, J.F.; Hsieh, H.N.; Do, Q.H. Evaluating teaching performance based on fuzzy AHP and comprehensive evaluation approach. Appl. Soft Comput. 2015, 28, 100-108. [CrossRef]

21. Asad, M.M.; Kermani, S.E.; Hora, H.R.M. A proposed framework for evaluating student's performance and selecting the top students in e-learning system, using fuzzy AHP method. In Proceedings of the International Conference on Management, Economics and Humanity (ICMEH), Istanbul, Turkey, 17 May 2015.

22. Mehregan, M.R.; Jamporazmey, M.; Hosseinzadeh, M.; Mehrafrouz, M. Application of fuzzy analytic hierarchy process in ranking modern educational systems' success criteria. Int. J. Educ. Bus. Manag. Learn. 2011, 1, 299-304. [CrossRef]

23. Anggrainingsih, R.; Umam, M.Z.; Setiadi, H. Determining e-learning success factor in higher education based on user perspective using fuzzy AHP. In MATEC Web of Conferences; EDP Sciences: Ulis, France, 2018; Volume 154, p. 03011.

24. Aliev, R.A.; Fazlollahi, B.; Aliev, R.R. Soft Computing and its Applications in Business and Economics; Springer: Berlin/Heidelberg, Germany, 2004.

25. Aliev, R.A.; Aliev, R.R. Soft Computing and its Applications; World Scientific: Singapore, 2001.

26. Bellman, R.E.; Zadeh, L.A. Decision-making in a fuzzy environment. Manag. Sci. 1970, 17, 141-164. [CrossRef]

27. Methodology for Overall and Subject Rankings for the Times Higher Education World University Rankings 2019. September 2018. Available online: https:/www.timeshighereducation.com/sites/default/files/the_2019_ world_university_rankings_methodology_pwc.pdf (accessed on 7 July 2020).

28. Cebi, A.; Karal, H. An application of fuzzy analytic hierarchy process (FAHP) for evaluating students' project. Educ. Res. Rev. 2017, 12, 120-132.

29. Nagpal, R.; Mehrotra, D.; Bhatia, P.K.; Sharma, A. FAHP approach to rank educational websites on usability. Int. J. Com. Dig. Sys. 2015, 4, 251-260. [CrossRef] 
30. Hota, H.S.; Pavani, S.; Gangadhar, P.V.S.S. Evaluating teachers ranking using fuzzy AHP technique. Int. J. Soft Comput. Eng. 2013, 2, 485-488.

31. Dovlatova, K.J. Estimation of the consistency index in fuzzy AHP based marketing channel selection problem. Sci. Work. 2019, 3, 248-254.

32. Prascevic, N.; Prascevic, Z. Application of fuzzy AHP method based on eigenvalues for decision making in construction industry. Tech. Gaz. 2016, 23, 57-64.

33. Aliyev, R.R.; Temizkan, H. Application of analytic hierarchy process method for ranking of universities. In Advances in Intelligent Systems and Computing; ICSCCW 2019; Springer Nature Switzerland AG: Cham, Switzerland, 2020; Volume 1095, pp. 772-780.

(C) 2020 by the authors. Licensee MDPI, Basel, Switzerland. This article is an open access article distributed under the terms and conditions of the Creative Commons Attribution (CC BY) license (http://creativecommons.org/licenses/by/4.0/). 